\title{
DISCUSSION
}

\section{Proposal for a new plasticity chart}

\author{
E. POLIDORI (2003). Géotechnique 53, No. 4, 397-406
}

K. S. Li, University of Hong Kong

Geotechnical engineers are normally not very well trained in the application of statistics in soil mechanics. Spurious observations or incorrect conclusions are therefore often made from graphical plots of soil data owing to inappropriate choice of variables in correlating different soil properties (Li \& White, 1993). The plasticity chart proposed by A. Casagrande, which has been used for decades as a tool for classification of soils, is a case in point.

In the plasticity chart, the plasticity index $I_{\mathrm{p}}$ is plotted against the liquid limit $w_{\mathrm{L}}$. Different types of clayey or silty soils tend to take up different zones in the plasticity chart. As pointed out by Li \& White (1993), the plasticity index is functionally related to the liquid limit by the equation $I_{\mathrm{p}}=$ $w_{\mathrm{L}}-w_{\mathrm{p}}$, where $w_{\mathrm{p}}$ is the plastic limit. Therefore a strong statistical correlation between $I_{\mathrm{p}}$ and $w_{\mathrm{L}}$ can be derived even if there is no strong statistical correlation between $w_{\mathrm{L}}$ and $w_{\mathrm{p}}$. By performing a simulation in which random numbers are generated for $w_{\mathrm{L}}$ and $w_{\mathrm{p}}$, Li \& White (1993) were able to obtain a statistically significant linear relationship between $I_{\mathrm{p}}$ and $w_{\mathrm{L}}$, as shown in Fig. 9, with a coefficient of correlation of 0.962 , yet this correlation has no meaning as $w_{\mathrm{L}}$ and $w_{\mathrm{p}}$ are unrelated.

Seed et al. (1964a) observed that $w_{\mathrm{L}}$ and $w_{\mathrm{p}}$ of organic clays with different activities follow different linear relationships in the plasticity chart, as shown in Fig. 10. As $I_{\mathrm{p}}$ and $w_{\mathrm{L}}$ are functionally related to each other, these linear relationships are very close to each other and occur within a narrow band close to the A-line. They can easily be masked by the innate variability and measurement errors of $w_{\mathrm{L}}$ and $w_{\mathrm{p}}$. It is therefore not entirely appropriate for Casagrande to choose to define the plasticity chart in terms of $w_{\mathrm{p}}$ and $w_{\mathrm{L}}$. A better way to discern the correlation of index properties is to use $w_{\mathrm{p}}$ and $w_{\mathrm{L}}$ directly as the variables for constructing the plasticity chart, hereafter called the P-L chart, as distinct from the conventional plasticity chart.

Figure 11 shows the data from Skempton (1953) and Seed et al. (1964a) plotted in a P-L chart. A comparison of Figs

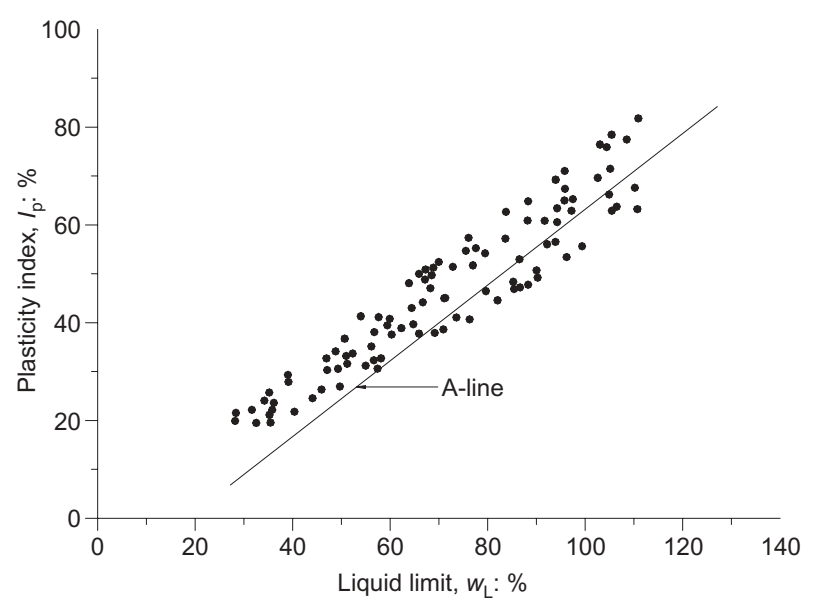

Fig. 9. Relationship between $I_{\mathrm{p}}$ and $w_{\mathrm{L}}$ based on randomly generated $w_{\mathrm{p}}$ and $w_{\mathrm{L}}$

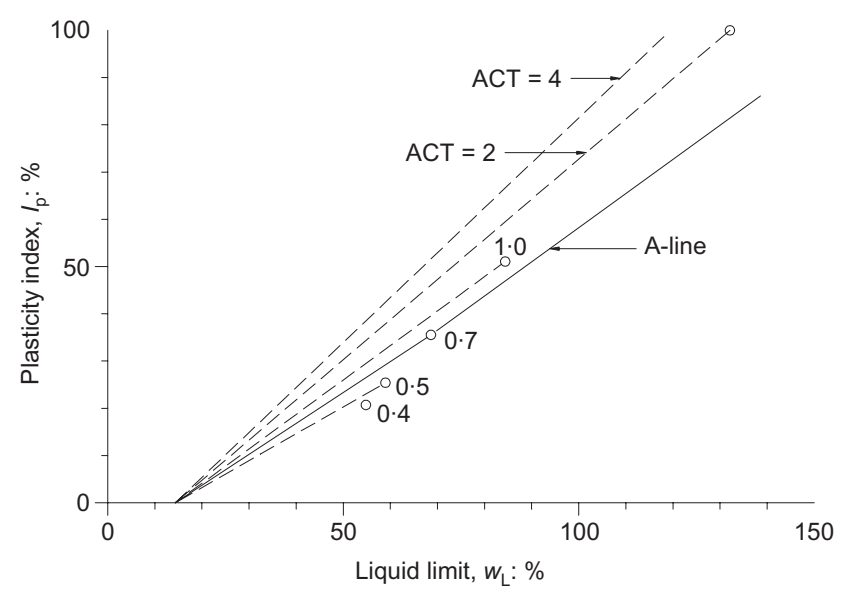

Fig. 10. Relationship between $I_{\mathrm{p}}$ and $w_{\mathrm{L}}$ for different activities of clay. ACT, activity of clay

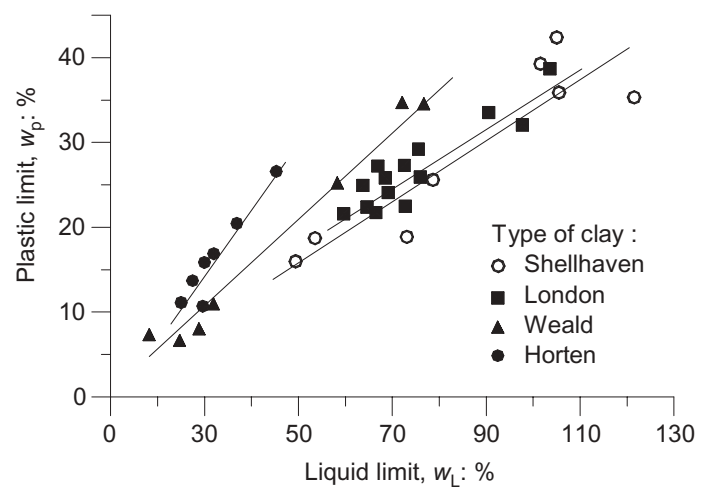

(a)

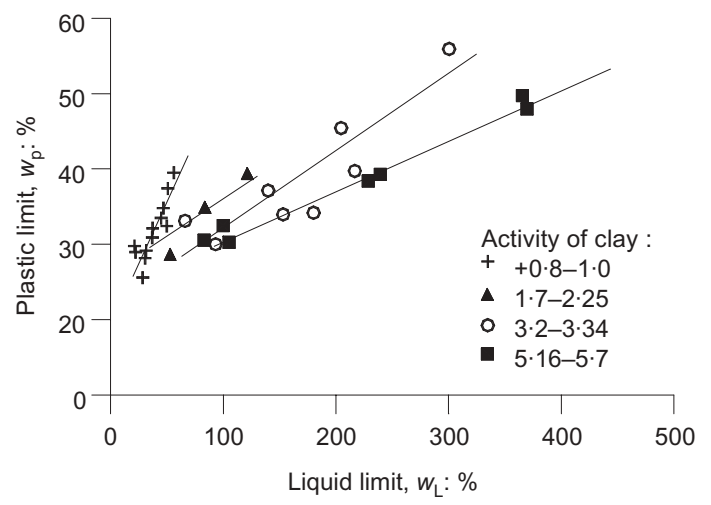

(b)

Fig. 11. P-L chart of clays: (a) data from Skempton (1953); (b) data from Seed et al. (1964a)

10 and 11 indicates that clays with different activities exhibit more distinct linear relationships in a P-L chart than in a conventional plasticity chart. This implies that different types of soil will tend to demarcate more distinctly in a P-L 
chart. For this reason, the P-L chart is considered to be a more powerful tool for soil classification. The author has given new insights into soil classification based on the conventional plasticity chart. It is therefore of interest to know whether an improved soil classification can also be developed using the suggested P-L chart.

\section{Author's reply}

The author thanks the discusser, although he believes the discussion does not specifically address the contents of this paper. In fact, the difference between the two $I_{\mathrm{p}}-w_{\mathrm{L}}$ plasticity charts (that of Casagrande and the author's) seems of lesser importance than the $w_{\mathrm{p}}-w_{\mathrm{L}}$ parameters with which the plasticity could be represented according to $\mathrm{Li}$.

Disregarding some inaccuracies (as in the graphs of Figs 10 and 11) which are not determinant, the fundamental issues in the author's view are as follows.

If it is true that 'a strong statistical correlation between $I_{\mathrm{p}}$ and $w_{\mathrm{L}}$ can be derived even if there is no strong statistical correlation between $w_{\mathrm{L}}$ and $w_{\mathrm{p}}$ ', it is not possible for the data (Skempton, 1953; Seed et al., 1964a) to show a more distinct linear relationship in the P-L chart (Fig. 11) than in the $I_{\mathrm{p}}-w_{\mathrm{L}}$ plasticity chart (Fig. 10). Independent of this consideration, on the basis of Fig. 2, plotting these data on the proposed plasticity chart one can observe-for example the data in fig. 5 of the study in discussion, indicated here as Fig. 12, and in the $w_{\mathrm{p}}-w_{\mathrm{L}}$ chart in Fig. 13-that both charts give equivalent information regarding the classification of the soils tested as well as their clay content (the

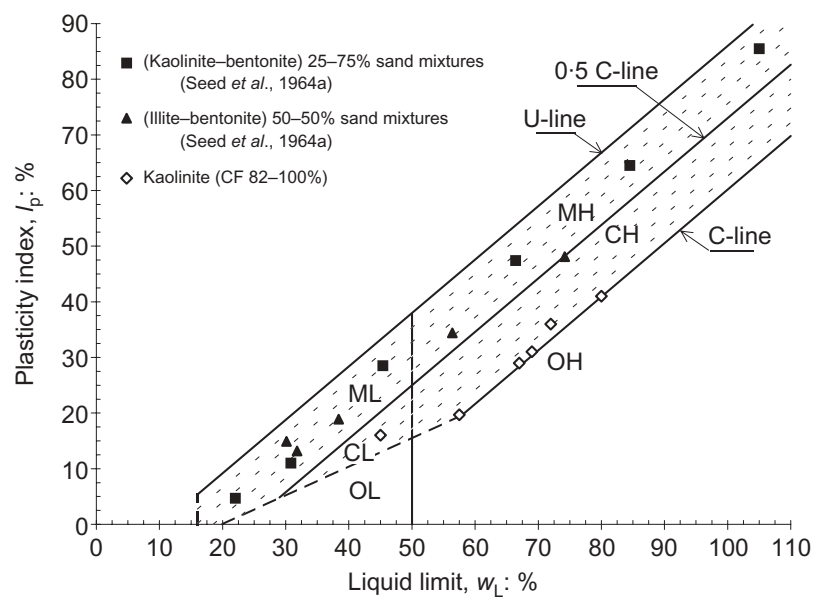

Fig. 12. Fig. 5 of the paper under discussion. The dashed lines represent the clay fraction $(\mathrm{CF})$ at $10 \%$ intervals

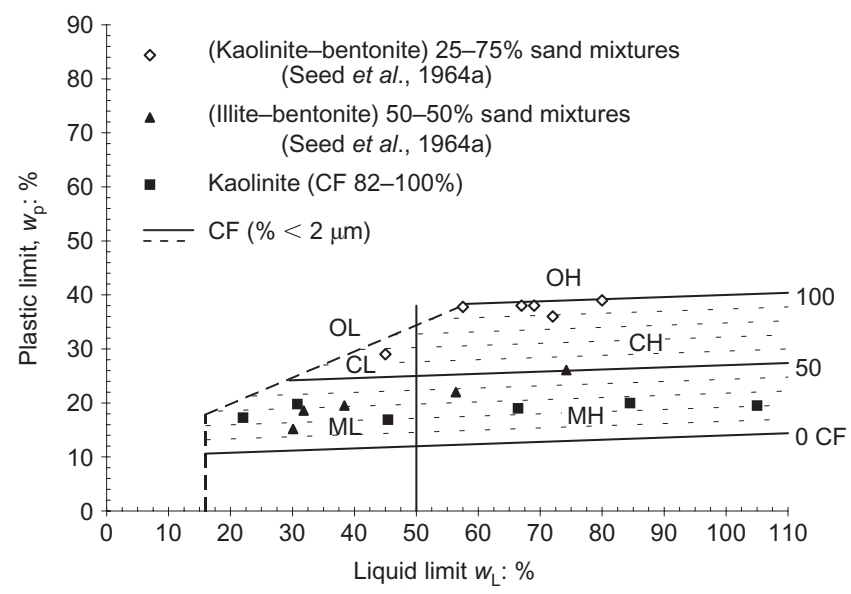

Fig. 13. Plastic limit, $w_{\mathrm{p}}$, against liquid limit, $w_{\mathrm{L}}$, of soils plotted in Fig. 12 proposed chart is better suited also for appraising the activity). It is clear that in the $w_{\mathrm{p}}-w_{\mathrm{L}}$ chart the silt and clay zones are reversed when compared with the $I_{\mathrm{p}}-w_{\mathrm{L}}$ plasticity chart.

\section{K. Prakash, Sri Jayachamarajendra College of Engineering, Mysore, India}

A. Sridharan, Indian Institute of Science, Bangalore, India

The author is to be complimented for creating a platform for a useful discussion on the issue of soil classification.

As the author had made clear, the paper was a result of the need to answer the following questions:

(a) Why do inorganic soils represented on Casagrande's plasticity chart, with clay fractions $(\mathrm{CF})<2 \mu \mathrm{m}$ that are smaller than their silt and/or sand fractions $(2-$ $425 \mu \mathrm{m})$, lie above the A-line in the clay zone?

(b) Conversely, why does pure kaolinite lie below the Aline in the silt zone?

The classification of fine-grained soils has three stages:

1. grain size analysis, which determines sand fraction, silt fraction and clay fraction

2. positioning of the fine-grained soil in the plasticity chart so as to judge whether the soil is inorganic clay, inorganic silt or organic soil

3. depending upon the liquid limit of the soil, deciding whether the soil has low, medium or high plasticity.

The first two stages should not be interlinked. Whereas the first stage considers only soil grain size, the classification of soil into silt or clay through a plasticity chart is based purely on plasticity: the liquid limit and plasticity index are the two parameters required to do so. In other words, the term 'silt size fraction' is different from the term 'silt', and the term 'clay size fraction' is different from the term 'clay'.

It is well established that clay minerals such as montmorillonite and kaolinite are responsible for soil plasticity. The type and quantity of clay minerals with their associated exchangeable cations present in a fine-grained soil control the extent of soil plasticity and volume change behaviour rather than the CF. For the same bentonite clay, depending upon the exchangeable cation, the liquid limit can vary several fold, whereas marginal variations are seen in the plastic limit (e.g. Sridharan et al., 1986a). The author recognises the importance of clay mineralogy. Fig. 14 shows that $w_{\mathrm{L}}$ and $\mathrm{CF}$ are not interrelated. Two types of engineering behaviour of soils - silty behaviour and clayey behaviour-are recognised. If the montmorillonitic clay mineral content in the $\mathrm{CF}$ is more, then the soil exhibits clayey behaviour and high plasticity (i.e. relatively high $w_{\mathrm{L}}$ and low $\left.w_{\mathrm{p}}\right)$. If the kaolinitic clay mineral content is more, then the soil exhibits silty behaviour and low plasticity (i.e. relatively low $w_{\mathrm{L}}$ and high $w_{\mathrm{p}}$ ). A given soil may have a CF less than $50 \%$, but if the quantity of montmorillonitic clay minerals within that dominates, then that soil lies above the A-line. On the other hand, a given soil may have a silt fraction less than $50 \%$, and if the quantity of kaolinitic clay minerals within that is dominant and the $\mathrm{CF}$ contains relatively inert particles, then the soil lies below the A-line. Hence Casagrande's plasticity chart classifies the given soil into silt or clay based on a behavioural standpoint rather than on the soil content based on particle size only. This is the answer to the first question posed by the author.

Even though kaolinite is a clay mineral, as it is coarser in size it is normally of silt size. Kaolinite clay mineral contributes to the silty type of soil behaviour. It has a higher plastic limit and hence less plasticity. Hence it is unsurprising to see pure kaolinite lying below the A-line in the silt zone. This is the answer to the authors' second question. 


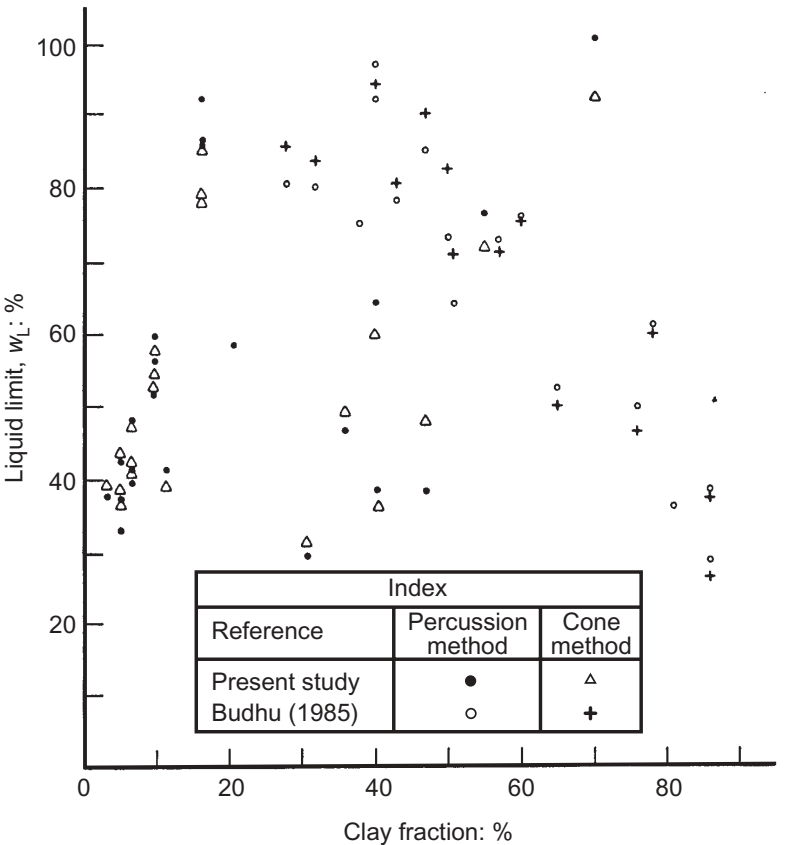

Fig. 14. Relationship between percent clay fraction content and liquid limit (Sridharan \& Prakash, 2000)

The discussers wish to present some more illustrations to highlight the limitations of the proposed plasticity chart (Fig. $15 \&$ Table 6). Fig. 15 shows the author's new plasticity chart along with the A-line of Casagrande's chart. The soils that fall in zone $\mathrm{p}$ are really silts from their behavioural viewpoint, but are classified as clays in the new plasticity chart. The inorganic clays that lie in zone q will be treated by the new chart as organic soils! The soils that locate themselves between the $0.5 \mathrm{C}$-line and U-line, particularly at high liquid limits, are classified by the new plasticity chart as silts. It should be noted that high plastic clays which can be regarded as expansive soils have high liquid limits and high plasticity indices. It is not correct to classify them as silts.

Soils $1-5$ in Table 6 have a CF content more than $50 \%$. They are classified by both British and ASTM standards as inorganic clays, whereas the proposed new plasticity chart treats them as silts. It can be noted that soils $1-3$ are expansive soils. Soil 6 is classified as silt of high plasticity by both British and ASTM standards even though its CF

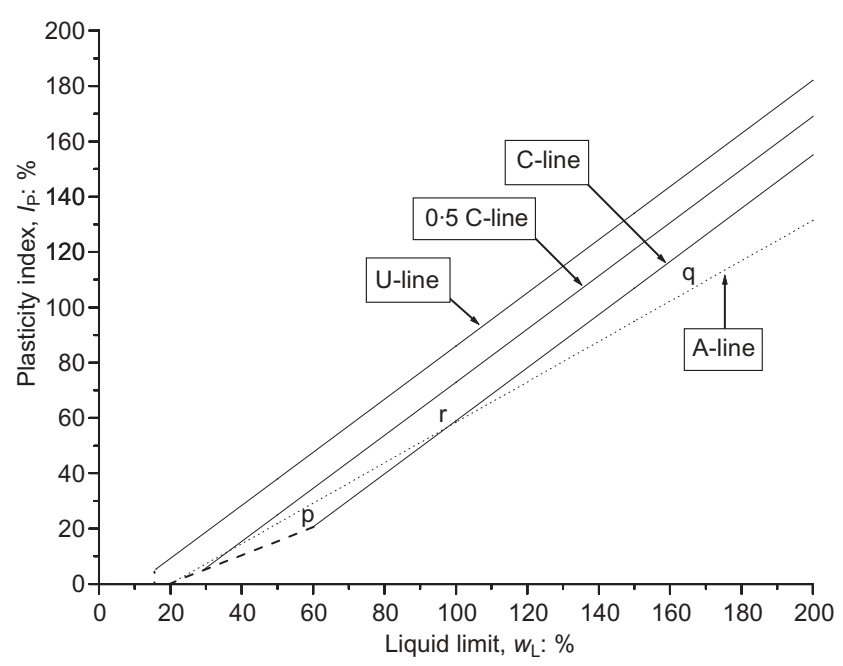

Fig. 15. New plasticity chart proposed by the author along with A-line content is more than $50 \%$. This is because of its silty behaviour due to the presence of kaolinite as its primary clay mineral.

Soils $7-18$ in Table 6 have a silt fraction more than 50\%. They are regarded as inorganic silts, true to their clay mineral composition, by the British and ASTM standards, whereas the proposed new plasticity chart of the author classifies them as either organic soils or clays. Soil 19, even though it has a silt fraction more than $50 \%$, is classified as clay of high plasticity by the British and ASTM standards. This could be due to the influence of dominant clay mineral content in the CF.

Soils $20-22$ in Table 6 have both CF and silt fractions less than $50 \%$. Soils 21 and 22 in particular are highly expansive inorganic clays, owing to the presence of dominant expansive clay mineral in the $\mathrm{CF}$, but the proposed new plasticity chart identifies them as silts!

In addition to the above, Table 1 assumes a linear variation of $w_{\mathrm{L}}$ and $w_{\mathrm{p}}$ with the CF content. Figs 16 and 17 show a variation of $w_{\mathrm{L}}$ and $w_{\mathrm{p}}$ with the $\mathrm{CF}$ content that is nonlinear. Many similar examples could be cited.

Finally, the discussers wish to conclude by stating that the classification of soils into clays and silts through a plasticity chart is nothing to do with the clay size fraction or silt size fraction, but it is from their plasticity behaviour. As the soil plasticity does not depend upon the content of clay-size and silt-size particles, the author's suggestion that the classification of silt or clay should be in agreement with the main component (silt size or clay size fraction) defined by the nomenclature for the grain size distribution of the soil fraction seems untenable.

\section{Author's reply}

The author wishes to thank Professor Prakash and Professor Sridharan for their discussion of the author's paper.

It should be noted that considerations regarding inorganic soils with platey clay minerals are not valid for residual inorganic soils containing non-platey clay minerals (allophane, halloysite, attapulgite) because their characteristics (high plastic limit, low plasticity index, high residual strength; Kenney, 1967; Lupini et al., 1981; Wesley, 1992; Mitchell, 1993) are very different from those of platey clay minerals for which the plasticity chart was developed. Hence these soils may lie below or above the C-line according to their particular characteristics.

Figure 18 shows all the soil values (25 in number) reported in Wasti \& Bezirci (1986). The clay fraction of these soils ranges from $13 \%$ to $88 \%$. All the soils lie above Casagrande's A-line and between the C-line and the U-line. The same is true of the soils plotted in Fig. 19.

According to the author, the classification of inorganic soils as silts or clays from a behavioural standpoint must be pursued exclusively in the zone between the U-line and the C-line in which the soils lie (see Fig. 18).

The classification of the soils (with $\mathrm{CF}<50 \%$ ) that lie between the $0.5 \mathrm{C}$-line and the U-line in the silt zone (such as soils no. 1, 19, 20, 21 and 22 in Table 6) should be different from the classification proposed by Casagrande. But some soils, including many of those chosen by the discussers and reported in Table 6 , lie in a zone that does not correspond to their clay fractions. The values of the Atterberg limits of these soils, if compared among themselves or with other data reported in the literature, may be difficult to understand, particulary $W_{\mathrm{P}}$. For example, soils no. 8 and no. 19 (Table 6) have the same $w_{\mathrm{L}}$ value and an almost equal percentage of clay. The respective values of the plastic limit are $w_{\mathrm{p}}=51.9 \%$ and $w_{\mathrm{p}}=25 \%$. What accounts for this difference of more than $100 \%$ ? Why is the difference among the $w_{\mathrm{p}}$ values greater than the difference among 
Table 6. Details of some typical soils

\begin{tabular}{|c|c|c|c|c|c|c|c|c|c|c|}
\hline \multirow[t]{2}{*}{ No. } & \multirow[t]{2}{*}{ Soil } & \multirow[t]{2}{*}{$w_{\mathrm{L}}: \%$} & \multirow[t]{2}{*}{$I_{\mathrm{p}}: \%$} & \multicolumn{3}{|c|}{ Grain size distribution } & \multicolumn{3}{|c|}{ Classification } & \multirow[t]{2}{*}{ Reference } \\
\hline & & & & $\begin{array}{c}\text { Clay size: } \\
\%\end{array}$ & $\begin{array}{l}\text { Silt size: } \\
\quad \%\end{array}$ & $\begin{array}{c}\text { Sand size: } \\
\%\end{array}$ & BS & ASTM & $\begin{array}{c}\text { Proposed } \\
\text { modified chart }\end{array}$ & \\
\hline 1 & Bentonite-sand mixture & 198 & $172 \cdot 6$ & 60 & - & 40 & $\mathrm{CE}$ & $\mathrm{CH}$ & MH & Sivapullaiah \& Sridharan (1985) \\
\hline 2 & Sample no. 17 & 362 & 333 & 84 & ? & ? & $\mathrm{CE}$ & $\mathrm{CH}$ & MH & Wasti \& Bezirci (1986) \\
\hline 3 & Sample no. 16 & 526 & 488 & 88 & $?$ & $?$ & $\mathrm{CE}$ & $\mathrm{CH}$ & MH & Wasti \& Bezirci (1986) \\
\hline 4 & Sample no. 06 & 52 & 30 & 59 & ? & $?$ & $\mathrm{CH}$ & $\mathrm{CH}$ & MH & Wasti \& Bezirci (1986) \\
\hline 5 & Red earth-2 & $51 \cdot 5$ & $30 \cdot 3$ & 62 & 38 & 00 & $\mathrm{CH}$ & $\mathrm{CH}$ & MH & Sridharan \& Prakash (1998) \\
\hline 6 & Bangalore soil & 70 & 31 & 66 & 28 & 06 & MH-MV & MH & $\mathrm{CH}$ & Sridharan et al. (1990) \\
\hline 7 & Korapet soil & 66 & 26 & 30 & 58 & 12 & MH & MH & $\mathrm{OH}$ & Sridharan et al. (1990) \\
\hline 8 & Illitic soil & $73 \cdot 4$ & $21 \cdot 5$ & $27 \cdot 5$ & $71 \cdot 6$ & $0 \cdot 9$ & MV & MH & $\mathrm{OH}$ & Sridharan \& Nagaraj (2000) \\
\hline 9 & Cochin soil & $56 \cdot 4$ & $18 \cdot 3$ & $17 \cdot 5$ & $64 \cdot 5$ & 18 & MH & MH & $\mathrm{CH}$ & Sridharan \& Nagaraj (2000) \\
\hline 10 & Kaolinite-3 & $58 \cdot 7$ & $13 \cdot 5$ & 11.5 & $88 \cdot 5$ & 00 & MH & MH & $\mathrm{OH}$ & Sridharan \& Nagaraj (2000) \\
\hline 11 & Peenya soil-7 & $72 \cdot 2$ & 25 & $15 \cdot 7$ & 80 & $4 \cdot 3$ & MV & MH & $\mathrm{OH}$ & Sridharan \& Prakash (1998) \\
\hline 12 & Hemavathi Project soil & $58 \cdot 5$ & $27 \cdot 5$ & $20 \cdot 8$ & $51 \cdot 2$ & 28 & MH & MH & $\mathrm{CH}$ & Sridharan \& Prakash (1998) \\
\hline 13 & Kaolinite-1 & 48 & $12 \cdot 4$ & 10 & $77 \cdot 5$ & $12 \cdot 5$ & MI & ML & $\mathrm{OL}$ & Sridharan \& Prakash (1998) \\
\hline 14 & Kaolinite-2 & $46 \cdot 8$ & $17 \cdot 4$ & 36 & $63 \cdot 6$ & $0 \cdot 4$ & MI & ML & CL & Sridharan \& Prakash (1998) \\
\hline 15 & Silty soil & $41 \cdot 4$ & $10 \cdot 9$ & $11 \cdot 5$ & $59 \cdot 7$ & $28 \cdot 8$ & MI & ML & CL-OL & Sridharan \& Prakash (1998) \\
\hline 16 & Bentonite-kaolinite mixture & 75 & $38 \cdot 6$ & 21 & 79 & 00 & MV & MH & $\mathrm{CH}$ & Satyanarayana Murthy (1986) \\
\hline 17 & $\mathrm{Na}-$ kaolinite & 52 & 13 & $11 \cdot 1$ & $81 \cdot 3$ & $7 \cdot 6$ & MH & MH & $\mathrm{OH}$ & Sivapullaiah et al. (1996) \\
\hline 18 & Mangalore soil & 73 & $32 \cdot 6$ & 21 & 66 & 13 & MV & MH & $\mathrm{OH}$ & Sridharan et al. (1988) \\
\hline 19 & CPRI soil & 74 & 39 & 30 & 58 & 12 & $\mathrm{CV}$ & $\mathrm{CH}$ & MH & Sridharan et al. (1988) \\
\hline 20 & Maddur soil & $60 \cdot 8$ & $37 \cdot 2$ & 36 & $38 \cdot 7$ & $25 \cdot 3$ & $\mathrm{CH}$ & $\mathrm{CH}$ & MH & Present study \\
\hline 21 & Gumballi soil & $214 \cdot 5$ & $193 \cdot 6$ & 42 & $25 \cdot 5$ & $32 \cdot 5$ & $\mathrm{CE}$ & $\mathrm{CH}$ & MH & Present study \\
\hline 22 & Chittoor soil & 123 & 100 & 39 & 28 & 33 & $\mathrm{CE}$ & $\mathrm{CH}$ & MH & Sridharan et al. (1990) \\
\hline
\end{tabular}




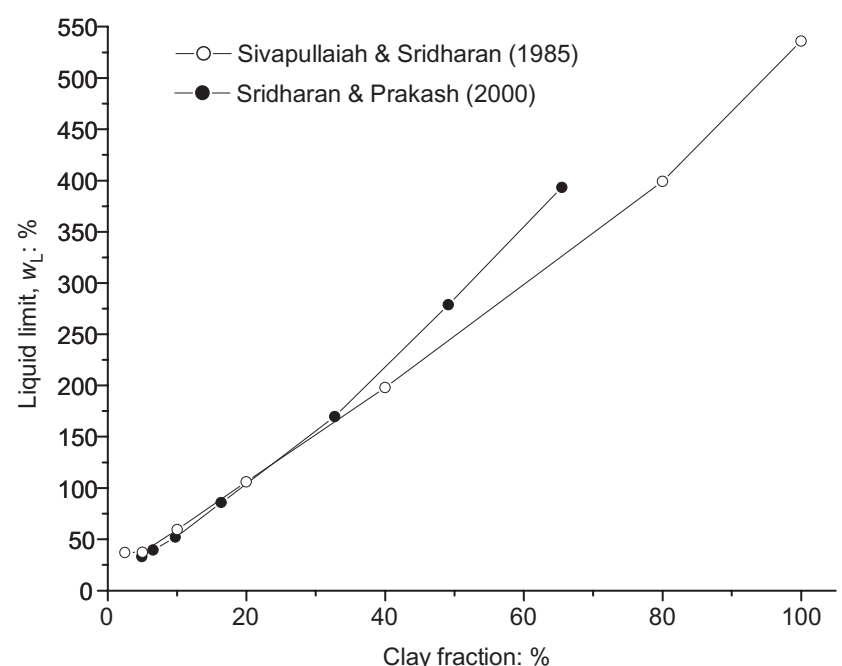

Fig. 16. Variation of liquid limit with clay fraction of the soil

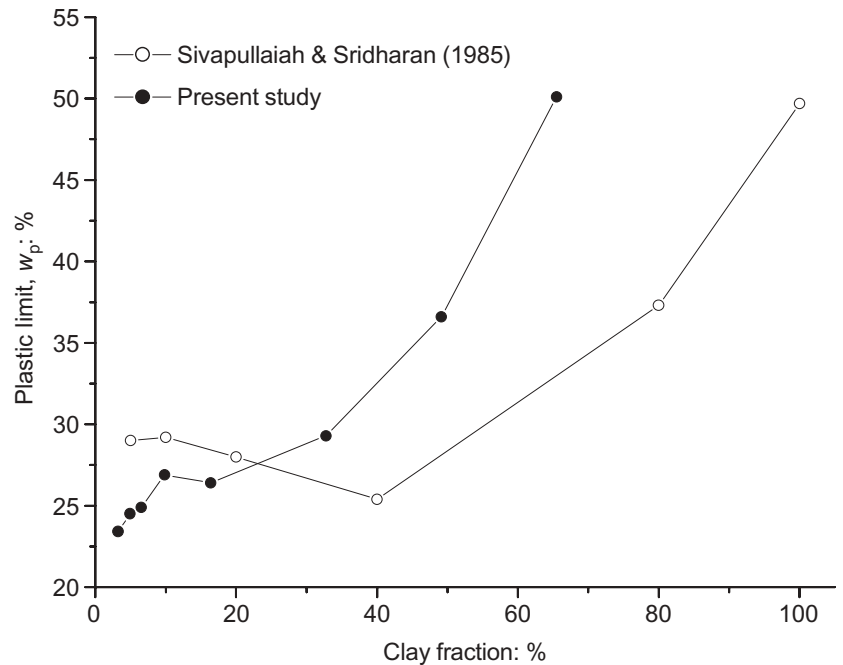

Fig. 17. Variation of plastic limit with clay fraction of the soil

the $w_{\mathrm{L}}$ values in soils no. 10 and no. 14 ? Why do soils no. 3 (with $w_{\mathrm{L}}=526 \%$ ), no. 6 (with $w_{\mathrm{L}}=70 \%$ ) and no. 17 (with $w_{\mathrm{L}}=52 \%$ ) have a nearly equal $w_{\mathrm{p}}$ value $(38-39 \%)$ ? Finally, why does the lowest plastic limit value (20.9\%)

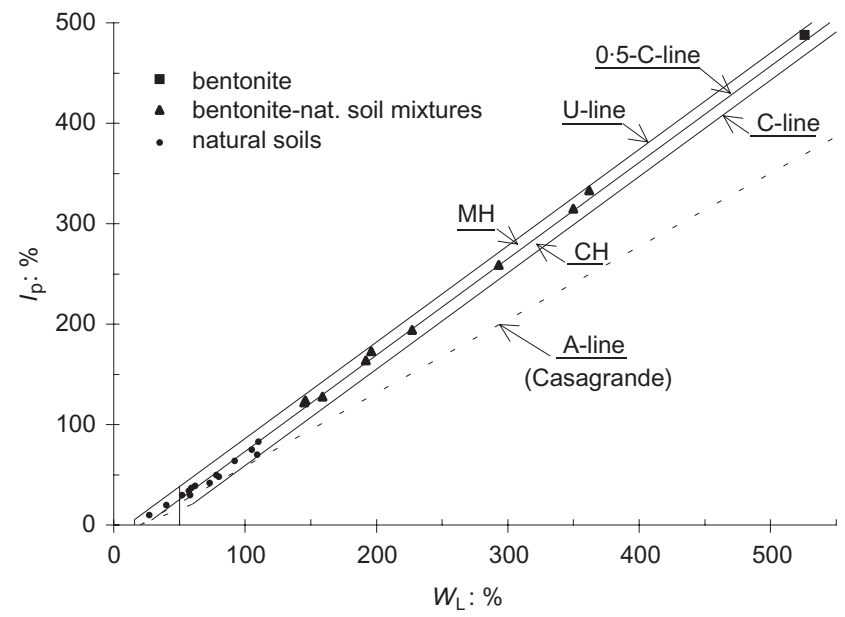

Fig. 18. Location on proposed plasticity chart of all soils (Wasti \& Bezirci, 1986). Casagrande's A-line is also shown

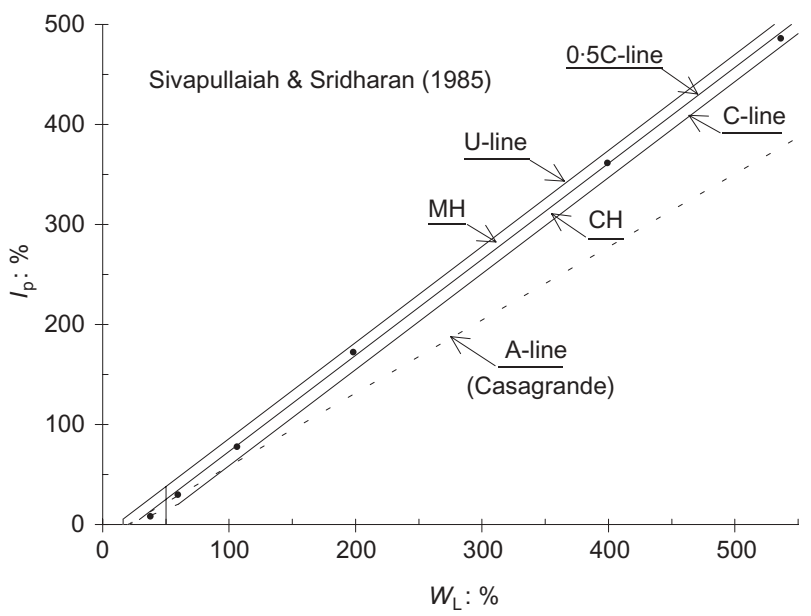

Fig. 19. Location on Polidori's plasticity chart of soils reported on discusser's Figs 16 and 17. Casagrande's A-line is also shown

belong to soil no. 21 with $w_{\mathrm{L}}=214,5 \%$ and $\mathrm{CF}=42 \%$ ? Table 7 shows several soils composed of only one clay mineral (from Table 6 and the literature). In particular, the plastic limit of the clay minerals kaolinite and montmorillo-

Table 7. Index properties of kaolinite and bentonite soils

\begin{tabular}{|c|c|c|c|c|c|c|c|}
\hline Sample no. & Soil/mineralogy & $w_{\mathrm{L}}: \%$ & $I_{\mathrm{p}}: \%$ & $w_{\mathrm{p}}: \%$ & CF: \% & $A$ & Reference \\
\hline 10 & Kaolinite-3 & $58 \cdot 7$ & $13 \cdot 5$ & $45 \cdot 2$ & $11 \cdot 5$ & $1 \cdot 17$ & Table 6 \\
\hline 13 & Kaolinite-1 & 48 & $12 \cdot 4$ & $35 \cdot 6$ & $9 \cdot 5$ & $1 \cdot 3$ & Table 6 \\
\hline \multirow[t]{7}{*}{14} & Kaolinite-2 & $46 \cdot 8$ & $17 \cdot 4$ & $29 \cdot 4$ & 36 & $0 \cdot 48$ & Table 6 \\
\hline & Kaolinite-quartz & 38 & $22 \cdot 7$ & $15 \cdot 3$ & 27 & $0 \cdot 84$ & Sridharan et al. (1988) \\
\hline & Kaolinite-quartz & 55 & $23 \cdot 6$ & $31 \cdot 4$ & 32 & $0 \cdot 74$ & Sridharan \& Nagaraj (2000) \\
\hline & Kaolinite-quartz & $31 \cdot 5$ & 15 & $16 \cdot 5$ & & & Sridharan et al. (2000) \\
\hline & Kaolinite-quartz & 37 & 19 & 18 & & & Sridharan et al. (2000) \\
\hline & Kaolinite-quartz & 44 & 26 & 18 & & & Sridharan et al. (2000) \\
\hline & Kaolinite-quartz & 48 & $26 \cdot 7$ & $21 \cdot 3$ & & & Sridharan et al. (2000) \\
\hline 1 & Bentonite-sand mixture & 198 & $172 \cdot 6$ & $25 \cdot 4$ & 40 & $4 \cdot 31$ & Table 6 \\
\hline \multirow[t]{9}{*}{3} & Bentonite & 526 & 488 & 38 & 88 & $5 \cdot 54$ & Table 6 \\
\hline & Bentonite & 536 & $486 \cdot 3$ & $49 \cdot 7$ & & & Figs 16,17 \\
\hline & Bentonite-sand mixture & 396 & $356 \cdot 7$ & $39 \cdot 3$ & 80 & & Figs 16,17 \\
\hline & Montmorillonite-quartz & 84 & 42 & 42 & 37 & $1 \cdot 13$ & Sridharan et al. (1986b) \\
\hline & Montmorillonite: round particles & 75 & $32 \cdot 5$ & $42 \cdot 5$ & 50 & $0 \cdot 65$ & Sridharan et al. (1986b) \\
\hline & Montmorillonite: round particles & 100 & $54 \cdot 8$ & $45 \cdot 2$ & 31 & $1 \cdot 77$ & Sridharan et al. (1986b) \\
\hline & Montmorillonite-quartz & $73 \cdot 5$ & $37 \cdot 9$ & $35 \cdot 6$ & 51 & $0 \cdot 74$ & Sridharan et al. (2000) \\
\hline & Montmorillonite-quartz & 98 & $49 \cdot 3$ & $48 \cdot 7$ & & & Sridharan et al. (2000) \\
\hline & Montmorillonite-quartz & 44 & $19 \cdot 4$ & $24 \cdot 6$ & & & Sridharan et al. (2000) \\
\hline
\end{tabular}


nite does not seem to follow any rules, either as a function of $\mathrm{CF}$ or as a function of the type of clay mineral (the plastic limit of montmorillonite should be $>$ (illite) $>$ kaolinite; White, 1949). In addition, some values of activity A do not seem typical of the clay minerals to which they belong.

Furthermore, it should be noted that classification problems arise using Casagrande's chart as well. For example, Fig. 3 shows several soils composed of kaolinite-quartz and other soils that contain just one clay mineral, montmorillonite (in addition, quartz, calcite, feldspar, etc.) taken from the literature. Considering that:

(a) morphologically, well-crystallised kaolinite is no larger than $4 \mu \mathrm{m}$ (lateral dimensions range from $0 \cdot 1$ to $4 \mu \mathrm{m}$, thickness from 0.05 to $2 \mu \mathrm{m}$; Mitchell, 1993), even though the characteristics of clay minerals are not (primarily) linked to the size of their particles, and

(b) kaolinite lies under the A-line and exhibits silt behaviour (according to the discussers),

the kaolinite-quartz mixtures (Fig. 20) that lie above the A-line are classified as clays. Is this right? Why do soils composed of montmorillonite and non-clay particles lie under the A-line? Is it right to classify them as silts? The sample (kaolinite-quartz, Fig. 20) that contains $11.5 \%$ kaolinite is classified as a silt with high plasticity, like samples containing about $50 \%$ montmorillonite.

The classification as silts or clays appears to be based on the kaolinite (= silt) and montmorillonite (= clay) contents, ignoring the content of round particles $(>2 \mu \mathrm{m})$. If the plasticity index values are equal, soils that have the highest liquid limit values (and thus lie below the A-line) exhibit silt behaviour (according to the discussers). In Fig. 20, for example, the kaolinite-quartz soil with $w_{\mathrm{L}}=38 \%, I_{\mathrm{p}}=$ $22.7 \%$ and $\mathrm{CF}=27 \%$ is classified as clay with low plasticity, whereas the kaolinite-quartz soil with $w_{\mathrm{L}}=55 \%$, $I_{\mathrm{p}}=23.6 \%$ and $\mathrm{CF}=32 \%$ is classified as silt with high plasticity. In this regard, Fig. 21 provides a concrete example of silt behaviour and clay behaviour.

Finally, if it is true that the colloidal activity of clays, defined by Skempton (1953), is $A=I_{\mathrm{p}} / \mathrm{CF}(\%<2 \mu \mathrm{m})$, clearly the plasticity of a given soil depends on both the type $(A)$ and the clay fraction $(\mathrm{CF})$. The author adopted a linear variation of $w_{\mathrm{L}}$ and $w_{\mathrm{p}}$ with the $\mathrm{CF}$ content, because if the relation between $w_{\mathrm{L}}, w_{\mathrm{p}}$ and $\mathrm{CF}$ was not linear then

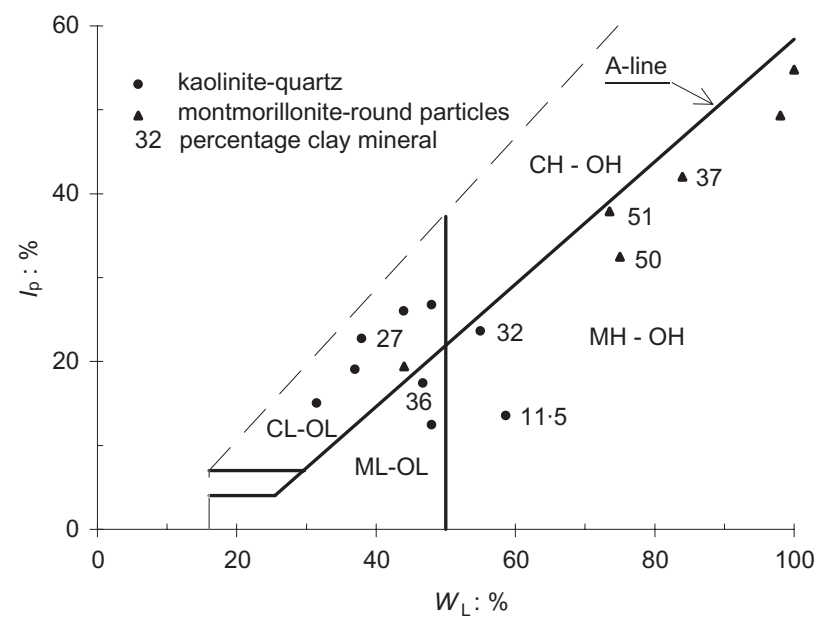

Fig. 20. Location on Casagrandes's plasticity chart (ASTM standard) of soils reported in Table 7

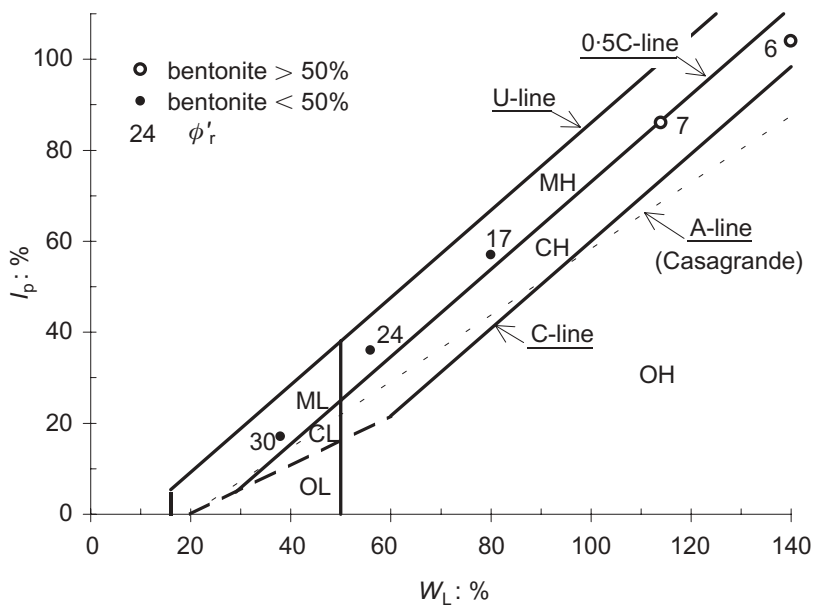

Fig. 21. Location on Polidori's plasticity chart of bentonite-sand mixures form Lupini et al. (1981). $\Phi_{\mathrm{r}}^{\prime}=$ residual friction angle (degrees). Casagrande's A-line is also shown

Skempton's linear relation $\left(I_{\mathrm{p}}, \mathrm{CF}\right)$, reported above would not be correct.

\section{REFERENCES}

Budhu, M. (1985). The effect of clay content on liquid limit from a fall cone and British cup device. Geotech. Test. J. 8, No. 2, 91-95.

Kenney, T. C. (1967). The influence of mineral composition on the residual strength of natural soils. Proceedings of the Geotechnical Conference, Oslo, vol. 1, pp. 123-129.

Li, K. S. \& White, W. (1993). Use and misuse of regression analysis and curve fitting in geotechnical engineering. In Probabilistic methods in geotechnical engineering (eds K. S. Li and S.-C.R. Lo), pp. 145-152. Rotterdam: Balkema.

Mitchell, J. K. (1993). Fundamentals of soil behaviour, 2nd edn. New York: Wiley.

Satyanarayana Murthy, N. (1986). Factors and mechanisms controlling volume change behaviour of fine-grained soils. $\mathrm{PhD}$ thesis, Indian Institute of Science, Bangalore, India.

Sivapullaiah, P. V. \& Sridharan, A. (1985). Liquid limit of soil mixtures. Geotech. Test. J. 8, No. 3, 111-116.

Sivapullaiah, P. V., Sridharan, A. \& Sreepada Rao, A. (1996). Effect of phosphate adsorption on the permeability of clays. Proc. 2nd Int. Cong. Environmental Geotechnics, Osaka, 597-602.

Sridharan, A. \& Nagaraj, H. B. (2000). Compressibility behaviour of remoulded, fine-grained soils and correlation with index properties. Can. Geotech. J. 37, No. 3, 712-722.

Sridharan, A. \& Prakash, K. (1998). Mechanisms controlling the shrinkage limit of soils. Geotech. Test. J. 21, No. 3, 240-250.

Sridharan, A., Rao, S. M. and Murthy, N. S. (1986a). Compressibility behaviour of homoionised bentonites. Géotechnique 36, No. 4, 551-564.

Sridharan, A., Rao, S. M. \& Murthy, N. S. (1986b). Liquid limit of montmorillonite soils. ASTM Geotech. Test. J. 9, 156-159.

Sridharan, A., Rao, S. M. \& Murthy, N. S. (1988). Liquid limit of kaolinitic soils. Géotechnique 38, No. 2, 191-198.

Sridharan, A., Rao, S. M. \& Joshi, S. (1990). Classification of expansive soils by sediment volume method. Geotech. Test. J. 13, No. 4, 375-380.

Sridharan, A., Nagaraj, H. B. \& Prasad, P. S. (2000). Liquid limit of soils equilibrium water content in one-dimensional normal compression. Proc. Inst. Civ. Engrs Geotech. Engng 143, 165-169.

Wesley, L. D. (1992). Some residual strength measurements on New Zealand soils. Proc. 6th Australia-New Zealand Conf. Geomechanics, Christchurch, 381-385.

White, W. A. (1949). Atterberg plastic limits of clay minerals. American Mineralogist 34, 508-512. 